\title{
ENDOMETRIOSE DO SEPTO RETO-VAGINAL
}

S.M.S, 29 anos, solteira, branca, técnica em microcomputadores.

Q.D. - Dor pélvica em cólica que se irradia para as costas e que piora no período menstrual há oito meses, juntamente com dor nas relações sexuais.

Exame Ginecológico - Mamas sem alterações.

Órgãos Genitais Externos - sem alterações.

Órgãos Genitais Internos - Nódulo palpável em I/3 superior da vagina, doloroso. Útero em MV pouco móvel, anexos irreconhecíveis.

Especular - Presença de dois nódulos avermelhados de $0,5 \mathrm{~cm}$ em I/3 superior $\mathrm{da}$ vagina.

Exames Subsidiários:

Ultra-sonografia pélvica transvaginal - útero de tamanho normal, ovários normais.

Hemograma $\mathrm{nl}$

Dosagem do CA I 25 - 64 (nl até 30-33)

H.D. Endometriose profunda com invasão para I/3 superior da vagina.

\section{Indicadavideolaparoscopia}

Após incisão intra-umbelical e colocação de ótica de $10 \mathrm{~mm}$ visualizou-se útero de tamanho normal, ovários de tamanho, forma e coloração normais.

Nota-se em fundo de saco de Douglas na região do septo reto-vaginal espessamento de peritoneo entre os dois ligamentosútero-sacros.

Optou-se pela dissecção do referido espessamento e como a correspondência desta lesão era o nódulo intra-vaginal, procedeu-se à abertura da cúpula da vagina por via videolaparoscópica. Confirmou-se que os nódulos que se viam na vagina correspondiam ao espessamento da região do septo reto-vaginal. Assim sendo, decidiu-se pela retirada de toda lesão endometriótica. A vagina foi suturada através da via videolaparoscópica.

O exame anatomopatológico mostrou presença de glândulas endometriais de permeio à musculatura lisa confirmou tratar-se de endometriose do septo reto-vaginal, invadindo $1 / 3$ superior da vagina.
A endometriose pode infiltrar e envolver várias estruturas pélvicas. Na sua forma profunda, invade a região do septo reto-vaginal podendo, como neste caso. infiltrar a vagina. Esta localização leva a paciente a dor e a dispareunia de profundidade. Como a localização deste tipo de endometriose é profunda, a dosagem do CA 125 tem especificidade alta (80-85\%). A ultra-sonografia costuma não mostrar alterações importantes neste tipo de endometriose.

O tratamento é sempre cirúrgico, consiste na retirada de toda lesão endometriótica. Após a retirada cirúrgica, o tratamento continua com inibição da atividade hormonal através do uso de análogos de GnRH por 3 a 4 meses.

A paciente, após cirurgia videolaparoscópica complementada pelo uso de acetato de leuprolide por quatro meses, refere meIhora do quadro clínico.

Como tratamento de manutenção para evitar recidivas, sugeriu-se o uso de contraceptivos orais de microdosagem.

Francesco VISCOMI

José Mendes Aldrighi

Faculdade de Saúde Pública da Universidade de São Paulo - S.Paulo - SP 